\title{
0750 PROMOTING HEALTHY AND SUSTAINABLE ENVIRONMENTS: OPPORTUNITIES FOR INJURY PREVENTION
}

P Pilkington* Correspondence: University of the West of England, Bristol, Glenside Campus, Blackberry Hill, Stapleton, Bristol, BS16 1DD, UK

\subsection{6/ip.2010.029215.750}

There is a renewed emphasis on the importance of place as a major health determinant, including the need to promote healthier and more sustainable environments and communities. This is in the main a response to two of the most pressing public health issues of our time; climate change and what has been termed the obesity epidemic, both of which can only be addressed adequately through significant changes to our environment and way of life. This paper discusses the opportunities that this situation presents for injury prevention. It identifies a number of injury prevention related initiatives that could be advanced by capitalising on the shared agendas of injury prevention, sustainability, and the need to promote physical activity, including the lowering of default speed limits in residential areas and the healthy design of residential developments. The paper also discusses how public health professionals, often responsible for the wider health of their population, are ideally placed to facilitate shared agendas by bringing together the multi-agency and multi-professional groups required to take forward policies. This includes initiatives that may, either directly or indirectly, prevent injuries. Such professionals can ensure that this common purpose leads to action and facilitates the prevention of injuries in our communities. 